\title{
Swelling Pressure of Soil using a Predictive Tool
}

\author{
V.V.N.Prabhakara Rao, PhD. \\ Professor, Department of Civil Engineering, \\ Pillai HOC College of Engineering and Technology, Rasayani, Dist. Raigad, Maharashtra, India.
}

\begin{abstract}
The characteristic of expansiveness represented by swelling pressure is considered as major parameter in design of engineering structures. In order to determine the potential expansion, the swelling pressure experiments are usually conducted. In the present study, neuronets have been used to predict swelling pressure of undisturbed as well as remolded soils from given geotechnical parameters such as grain-size distribution, consistency limits, activity, and deferential free swell. Neuronet models relating the potential expansiveness to some geotechnical properties are derived in order to overcome the need to perform lengthy swelling pressure determination experiments. While the remolded soil neuronets (Testing sets) developed in this study might be considered as specific, the remolded soil neuronets (Training sets) can be used to predict swelling characteristics for most soils in India or elsewhere in the world. Similarly the combined datasets used in training \& testing may significantly assist earthwork engineers in designing the sub grades and control the detrimental effect caused by volume changes associated with swelling of soil for roads, canals, buildings etc. Moreover, a neural network used in the prediction of expansion may assist the designers in selection of the appropriate water content to compact clays.
\end{abstract}

\section{Keywords}

Swelling Pressure, Neuronets, Input layer, Input variables, Hidden layer, Output layer.

\section{INTRODUCTION}

The fine-grained soils containing expansive minerals undergo swelling upon ingress of water. The swelling of clays depends upon type of clay mineral (Amount of mineral montmorillonite), orientation of clay particles, moisture content and surcharge weight. Whenever swelling is restrained, swelling pressure develops. The swelling pressure plays an important role in the design of structures. The swelling pressure is often determined in engineering projects wherever the proposed structures restrict the soil expansion. These structures may include residential projects, irrigation canals, earthen dams, highway embankments etc.

At the laboratory scale, swelling pressure is determined by Alpan's [1] method. Some of the other methods like Constant volume swell pressure test, different pressures method, double odometer method, swell consolidation method and their limitations are listed in Table No. 1.

The development of artificial neural networks (Neuroses) received wide interest from the researchers Flood and Kartam (1994). They have concentrated on understanding the usage and potential for application of neuronets in Civil Engineering. They have concentrated on most popular class of neuronet systems and looked at how and why such a system works and the primary issues concerning its use. Later on, the application of neuronets in constitutive modeling received attention from
Ghaboussi [3] they concentrated more on the basic methodology for the development of neuronets in materials models and have presented an example application to model the tri-axial behavior of sands. Whereas, Dayakar and Rongda [2] developed their neuronet-based sand models to model the drained tri-axial compression behavior of sands under low \& high confining pressures. The effect of mineralogy, particle shape \& size distribution, initial voids ratio \& confining pressure on the stress strain \& volume change behavior of sands has been studied. The only application to a problem with a field application was taken up by Shahim [9] in which they retro-predicted the amount of settlement a given shallow foundation can undergo for a given soil parameters.

It is seen from the literature that there has never been an attempt to either consider/incorporate the swelling pressure of soil in the design of earthen structures nor there is there is any method to predict it with the available resources at construction sites. In view of this, in the present paper, the author presents a neuronet model which can predict the swelling pressure, based on the generalized soil properties at any site.

\section{NEED FOR A NEW TECHNIQUE SUCH AS ANN}

During the execution of most of the engineering structures dealing with soils, the index properties, plasticity characteristics \& unconfined compressive strength of soil would be available but not the most important parameter indicative of soil expansion i.e. swelling pressure and field engineers keep wondering about the ways and means of quantifying soil expansion. There are two options to address this problem:

a) Physical measurement and usage of regression methods for futuristic prediction of probable heave,

b) Use of Predictive Tools viz., "Neuronets". While the regression methods develop an equation between the known values and the value to be predicted through an equation, the equation gives out an error, which cannot be eliminated. Predictive Tools give more weight age to actual measurement and at the same time bring out the difficulties to do so repeatedly at site. Especially, neuronet learns the underlying relation between the variables through the existing patterns. The error generated hence is back propagated through the inter-connecting weights between different layers, which, in turn, produce precise value of the output.

\section{THE OBJECTIVES}

The primary objectives of the present paper are:

1) To develop a neural network model to predict the swelling pressure from the basic engineering properties of soil viz., Soil type, gradation and consistency limits and free swell.

2) To address the advantage of the proposed neural network 
technique in predicting the swelling pressure of soil in the absence of testing facility.

\section{NEURONET MODEL}

Neuronets (Artificial Neural Networks) are the techniques that have adequate capabilities of learning intelligently all of the patterns present in a large database that yields a specific output. A network that efficiently captures the underlying relationships between input and the output can be utilized as a tool for predicting the cases where the output solution is readily not available. The three layered feed-forward, error-back propagation neuronets with supervised learning has been used in many application fields of science and engineering. In this type of neuronets, learning is accomplished by first assigning random connection weights, and finally back-propagating the error (Difference between the actual and competed outputs) through hidden layer. This procedure is repeated for all training data sets until the actual and calculated outputs agree within some predetermined tolerances. At this stage the network is saved for further use as a tool for prediction. Similar back propagation networks have been successfully employed to solve numerous engineering problems.

\section{DATA COLLECTION}

The data utilized in the present analysis is taken from a study made by the author, out of a total of 20 cases of laboratory testing of Soil samples, 15 cases (Approximately $75 \%$ of the total data sets) were used in training the neuronets as shown in Table 2 and 5 cases were used for testing as listed in Table 3. (Approximately $25 \%$ of the total data sets). The swelling pressure is determined only by "Constant Volume Method". The sets used in testing are indicative of expansion viz., Grain size analysis, Consistency limits, Free swell and Activity. On the other hand, the swelling pressure is fixed as the desired output variable of the neuronets.

\section{SELECTION OF INPUT AND OUTPUT PARAMETER}

The number of input and output nodes is fixed based on the selected input parameters and the desired output variables. The number of nodes in hidden layer is obtained by an interactive procedure. In this paper various neuronets are developed by varying the number of nodes in the input layer ( 9 to 7 ), hidden layer (15 to 10$)$ and number of hidden layers. This has been done in order to test the accuracy of the several neuronet topologies in predicting the desired outputs as shown in Table 4. The selection strategy of the various parameters from the input parameter list is by assuming that they are most influential to swelling pressure. The parameters such as Grain size, Atterberg's limits are most influential whereas Differential Free swell and Activity qualitatively indicate soil expansion.

\section{NETWORK TRAINING AND TESTING}

All the input and output parameters are normalized to vary between 0 and 1 to prevent larger values in one parameter from overriding smaller values in other parameters. The normalization of data has been found to accelerate the process of learning in many applications. The normalization is performed by using the expression, "Normalized value = Current value parameters/ Maximum value" of the parameters under consideration in a particular vector. After the neuronet had learned the pattern embedded in the training sets as shown in Table 5, the network is then examined for its prediction accuracy. This is done by allowing the developed neuronet to predict "Swelling Pressure" based on the data of the testing sets as shown in Table 6 . The predictions and the actual values of swelling pressure are compared using the percentage "Absolute Value Of Relative Error" given as ARE $-\left\{\left(\mathrm{X}_{\text {Pred }}-\mathrm{X}_{\text {Expt }}\right) /\right.$ $\left.\left(\mathrm{X}_{\text {Expt }}\right)\right\}^{*} 100 \%$. Since there are several testing sets selected randomly from the original databases, the "Mean" of the ARE (MARE) is used as the criterion for selecting the most accurate neuronet, as shown in Table 7.

\section{RESULTS AND DISCUSSION}

The results are presented in Table 1 to 7 .

\section{Discussion:}

Several neuronets varying by their architecture are developed and are tested for their adequacy in predicting the swelling characteristics (A1, B1, C1, C2, C3, D1, D2, D3, E1, E2, E3, F). Prediction accuracy of networks (C1-E3) is shown in Fig.1 \& 2.

It is to be mentioned herein that Table 7 only shows those cases where the neuronets were framed to give the best prediction performance for the five testing sets presented in Table 6 . This was done by varying number of input nodes and hidden layers and performing the necessary analysis assisted by ANN.

The value of swelling pressure thus obtained from the analysis (1000 Iterations) is compared with the experimental values and then, the associated Average Relative Error, Mean Average Relative Error, Correlation Coefficient \& Coefficient of Determination are computed.

Table 7 summarizes the different neuronets studied along with MARE, (Mean Average Relative Error), Correlation Coefficient(r), Coefficient of Determination [COD] computed for each of these neuronets.

Neuronet $\mathrm{Al}$ utilizes all nine variables i.e. $\% \mathrm{~S}$ Sand, \%M Silt \& \% C Clay, $\mathrm{W}_{\mathrm{L}}$ Liquid Limit, $\mathrm{P}_{\mathrm{L}}$ Plastic Limit, $\mathrm{S}_{\mathrm{L}}$ Shrinkage Limit, $I_{P}$ Plasticity Index, A Activity ,FS Free Swell in the input and 15 nodes on single hidden layer .

While network B1 is has been developed with number of nodes on the input layer remaining the same and number of nodes on the hidden layer is reduced to 12 .

In the neuronet $\mathrm{CI}$, the number of nodes on the input layer is still maintained and number of nodes on the hidden layer is reduced to 10 .

In the neuronet D1, "Activity" has been eliminated from the list of nodes in the input layer and still the number of nodes in the single hidden layer has been maintained as 10 nodes.

In the neuronet D2, input nodes in the input layer remained the same i.e. eight whereas there are 10 nodes on each of the two hidden layers,

While in the neuronet D3 all the input nodes used in D1 have been used but number of nodes in the hidden layer increased to three while keeping the number of nodes hidden layer as 10 . While, in the neuronet El to E3, Plasticity index is eliminated from the list of input nodes. The number of hidden layers in the neuronets El, E2, E3 is respectively one, two and three, but number of nodes in each of the hidden layers has been kept as ten.

It can be seen from Table 7 that neuronets C1-E3 compare to each other in terms of COD \& MARE. Out of these, for neuronets $\mathrm{Al}, \mathrm{Bl}, \mathrm{CI}, \mathrm{C} 2, \mathrm{D} 3 \mathrm{\&}$ E2 Correlation Coefficient is of negative value indicating the inverse relation between input and output variables. While the COD for these neuronets ranges between $69.75 \%$ and $99.92 \%$. Meanwhile, for neuronets C3, D1, D2, El, \& E3, the Correlation Coefficient is the positive value indicating the direct relation between input and output variables. While the COD for these neuronets lies between $98.1 \%$ and $98.9 \%$

It is thus evident from the above analysis that as the number of input variables is systematically reduced to seven in place of initial nine values, the swelling pressure values predicted by ANN are very closer to the swelling pressure values 
determined by "Constant Volume Method". A number of numerical experiments were conducted on choosing the number of hidden layers \& the nodes in them. It is found that,
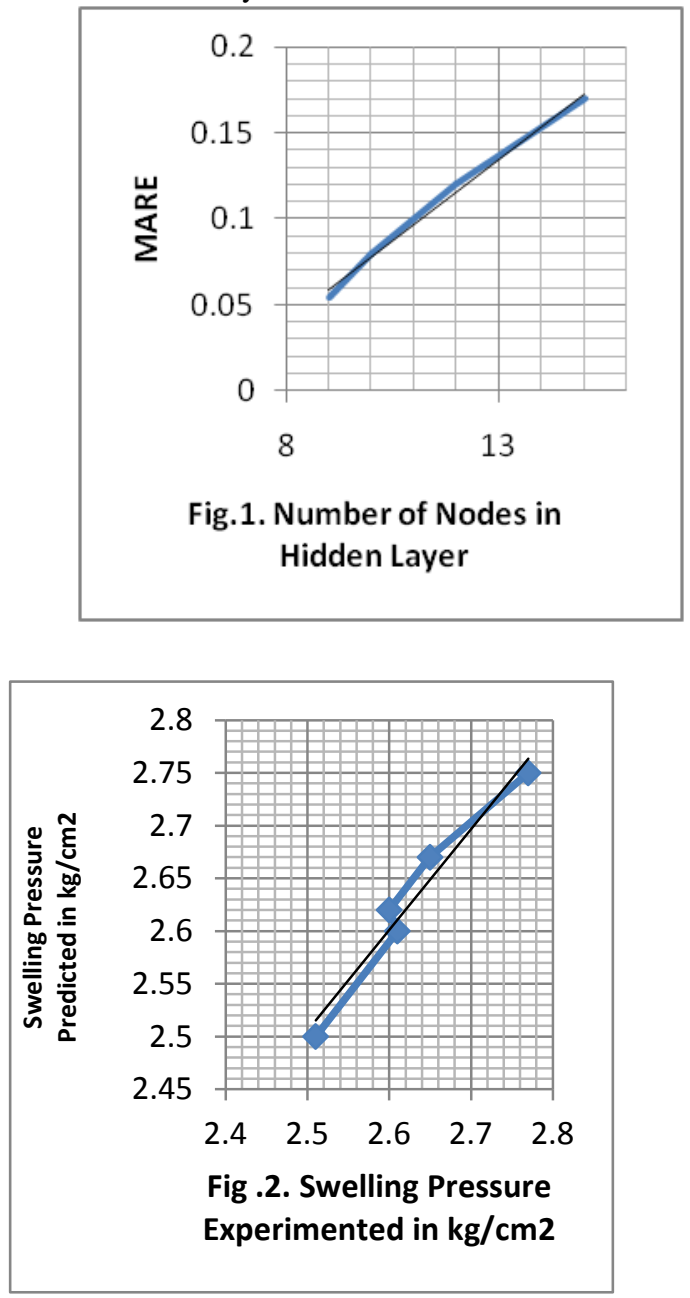

as commonly adopted, one hidden layer is adequate.

Fig.2 shows the relation between the values of swelling pressure that were obtained experimentally \& predicted with the help of neuronet. It can be clearly noticed that all the points are scattered about a 45" line, justifying the pattern identification by neuronets in the prediction of swelling pressure that were obtained experimentally.

However, examining the values listed in the Table 4 , it is obvious that, the neuronets with seven input nodes \& three hidden layers might be assumed to give accurate prediction of swelling pressure.

It is observed from Fig. 1 that ten hidden nodes give out minimum MARE. The variation of predictions as opposed to the experimented values of swelling pressure as shown in Fig.2 suggests a very close correlation between experimental \& predicted values of swelling pressure.

It is found that, as commonly adopted, one hidden layer is adequate. Fig.2 shows the relation between the values of swelling pressure that were obtained experimentally \& predicted with the help of neuronet. It can be clearly noticed that all the points are scattered about a $45^{\circ}$ line, justifying the pattern identification by neuronets in the prediction of swelling pressure that were obtained experimentally.

However, examining the values listed in the Table 4, it is obvious that, the neuronets with seven input nodes \& three hidden layers might be assumed to give accurate prediction of swelling pressure. It is observed from Fig.1 that the architecture with ten hidden nodes gives out minimum MARE. The variation of predictions as opposed to the experimented values of swelling pressure as shown in Fig. 2 suggests a very close correlation between experimental \& predicted values of swelling pressure.

Table 1. Comparison of various methods of determining swelling pressure.

\begin{tabular}{|c|c|c|c|}
\hline \multirow[t]{2}{*}{ Name of the Method } & \multicolumn{3}{|c|}{ Merits and Demerits } \\
\hline & & Merits & Demerits \\
\hline $\begin{array}{l}\text { Constant volume Swell } \\
\text { Pressure Method }\end{array}$ & c) & $\begin{array}{l}\text { Experimental Procedure versatile } \\
\text { and results fairly accurate. } \\
\text { Standardized Equipment is readily } \\
\text { available in the market. } \\
\text { Rational estimation of Load which } \\
\text { could be applied such that the heave } \\
\text { developed is tolerable. }\end{array}$ & $\begin{array}{l}\text { a) Experimental procedure does not simulate field } \\
\text { condition as the weight of the structure in } \\
\text { service does not change with time } \\
\text { b) This procedure necessitates uninterrupted } \\
\text { presence of the personnel throughout the } \\
\text { experiment. } \\
\text { c) Experiment consumes relatively longer time }\end{array}$ \\
\hline Different Pressures Test & a) & $\begin{array}{l}\text { Soil Sample in consolidometer is } \\
\text { subjected to uniform pressure all } \\
\text { through its thickness. } \\
\text { Suitable to big projects }\end{array}$ & $\begin{array}{l}\text { a) Sample in consolidometer is laterally confined } \\
\text { and suffers good amount of side friction. } \\
\text { b) Requires a large number of similar soil samples. }\end{array}$ \\
\hline Double Odometer method & a) & $\begin{array}{l}\text { Swelling pressure of higher order is } \\
\text { produced }\end{array}$ & $\begin{array}{l}\text { a) It does not require normal sequence of } \\
\text { loading-submersion of soil sample. }\end{array}$ \\
\hline $\begin{array}{l}\text { Swell Consolidation } \\
\text { method }\end{array}$ & & $\begin{array}{l}\text { Most favorable to pre-consolidated } \\
\text { clays }\end{array}$ & $\begin{array}{l}\text { The pressure required to compress the } \\
\text { pre-wetted sample is higher than other methods }\end{array}$ \\
\hline
\end{tabular}


Table 2. Soil Test Data Sheet for Training: Prabhakara Rao. (2012)

\begin{tabular}{|c|c|c|c|c|c|c|c|c|c|c|}
\hline$\dot{\vec{n}}$ & 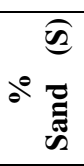 & 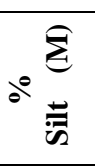 & $\begin{array}{l}0 \\
\vec{b} \\
0 \\
0 \\
0\end{array}$ & 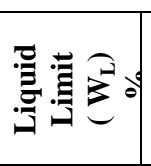 & 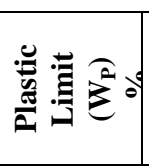 & 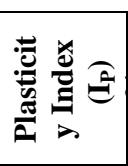 & 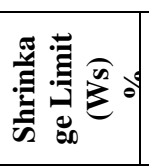 & 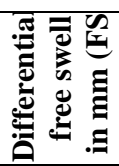 & 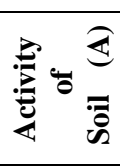 & 。 \\
\hline 1 & 12 & 29 & 59 & 68 & 28 & 40 & 12 & 150 & 0.667 & 2.77 \\
\hline 2 & 18 & 39 & 52 & 66 & 33 & 33 & 14 & 120 & 0.635 & 2.65 \\
\hline 3 & 19 & 34 & 47 & 69 & 30 & 39 & 10 & 130 & 0.83 & 2.6 \\
\hline 4 & 20 & 34 & 46 & 65 & 29 & 36 & 12 & 140 & 0.782 & 2.61 \\
\hline 5 & 17 & 39 & 44 & 67 & 30 & 37 & 11 & 150 & 0.841 & 2.51 \\
\hline
\end{tabular}

Table 3. Soil Test Data Sheet - for Testing: Prabhakara Rao. (2012)

\begin{tabular}{|c|c|c|c|c|c|c|c|c|c|c|}
\hline 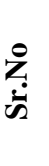 & 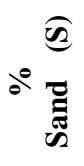 & $0 \begin{array}{l}\hat{E} \\
\text { 卷 }\end{array}$ & $\underbrace{\vec{\Phi}}_{0} 0$ & 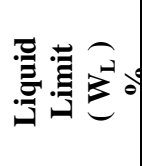 & 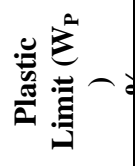 & 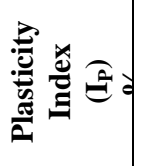 & 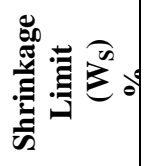 & 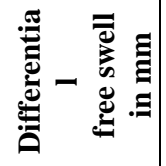 & 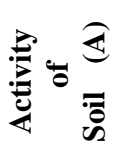 & 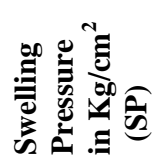 \\
\hline 1 & 32 & 24 & 44 & 58 & 23 & 35 & 12 & 71 & 0.800 & 1.16 \\
\hline 2 & 30 & 34 & 36 & 59 & 25 & 34 & 11 & 93 & 1 & 1.43 \\
\hline 3 & 22 & 26 & 52 & 86 & 19 & 67 & 9 & 188 & 1.230 & 2.79 \\
\hline 4 & 33 & 22 & 45 & 60 & 24 & 36 & 10 & 151 & 0.800 & 1.69 \\
\hline 5 & 14 & 49 & 37 & 65 & 15 & 50 & 11 & 115 & 1.310 & 2.56 \\
\hline 6 & 24 & 26 & 50 & 53 & 20 & 33 & 14 & 180 & 0.660 & 2.79 \\
\hline 7 & 5 & 15 & 80 & 94 & 24 & 70 & 16 & 220 & 0.897 & 3.77 \\
\hline 8 & 19 & 30 & 51 & 63 & 23 & 40 & 10 & 190 & 0.862 & 2.43 \\
\hline 9 & 26 & 24 & 50 & 63 & 28 & 35 & 8 & 328 & 0.620 & 2.68 \\
\hline 10 & 16 & 30 & 54 & 64 & 20 & 44 & 12 & 300 & 0.820 & 2.57 \\
\hline 11 & 15 & 37 & 48 & 58 & 17 & 41 & 13 & 265 & 0.820 & 2.65 \\
\hline 12 & 16 & 30 & 54 & 66 & 26 & 40 & 12 & 288 & 2.330 & 2.72 \\
\hline 13 & 18 & 31 & 51 & 64 & 22 & 42 & 10 & 420 & 0.857 & 3.42 \\
\hline 14 & 17 & 37 & 46 & 56 & 23 & 33 & 12 & 330 & 0.822 & 3.13 \\
\hline 15 & 13 & 36 & 51 & 60 & 23 & 37 & 13 & 237 & 0.667 & 3.28 \\
\hline
\end{tabular}

Table 4. Swelling Pressure predicted by Neuronet

\begin{tabular}{|c|c|c|c|c|}
\hline Topology 1 (9,15,1) & Topology 2 (9,12,1) & Topology 3 (9,10,1) & Topology 4 (8,10,1) & Topology 5 (7,10,1) \\
\hline 2.83 & 2.84 & 2.82 & 2.8 & 2.75 \\
\hline 2.61 & 2.58 & 2.64 & 2.61 & 2.67 \\
\hline 2.49 & 2.54 & 2.61 & 2.63 & 2.62 \\
\hline 2.55 & 2.48 & 2.54 & 2.58 & 2.6 \\
\hline 2.43 & 2.46 & 2.52 & 2.54 & 2.5 \\
\hline
\end{tabular}

For Example, Topology Means:

Number of Input Node=9, Number of Hidden Nodes-15, Number of Output Nodes-1

Table 5. Training File

\begin{tabular}{|c|c|c|c|c|c|c|c|c|c|}
\hline 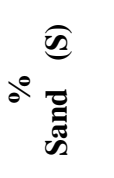 & 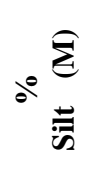 & $\underset{0^{\circ}}{\vec{\Xi}}$ & 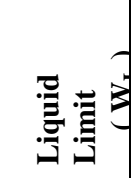 & 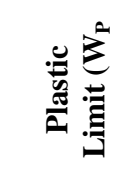 & 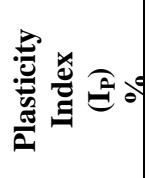 & 焉 & 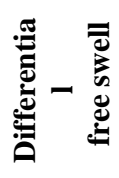 & 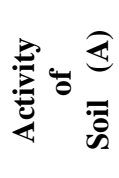 & 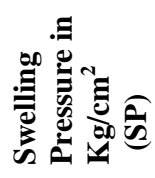 \\
\hline 0.9696 & 0.4898 & 0.5500 & 0.671 & 0.8214 & 0.5000 & 0.7500 & 0.1690 & 0.3430 & 0.3077 \\
\hline 0.9091 & 0.6939 & 0.4500 & 0.6277 & 0.8929 & 0.4857 & 0.6875 & 0.2214 & 0.4290 & 0.3793 \\
\hline 0.6667 & 0.5306 & 0.6500 & 0.9149 & 0.6786 & 0.9571 & 0.5625 & 0.4476 & 0.5290 & 0.7400 \\
\hline 1 & 0.4490 & 0.5625 & 0.6383 & 0.8571 & 0.5243 & 0.6250 & 0.3595 & 0.3430 & 0.4482 \\
\hline 0.4242 & 1 & 0.4625 & 0.6915 & 0.5371 & 0.7142 & 0.6875 & 0.2738 & 0.5620 & 0.6790 \\
\hline 0.7272 & 0.5306 & 0.6250 & 0.5638 & 0.7143 & 0.4714 & 0.8750 & 0.4286 & 0.2830 & 0.7400 \\
\hline 0.1515 & 0.3061 & 1 & 1 & 0.8571 & 1 & 1 & 0.5238 & 0.3580 & 1 \\
\hline 0.5758 & 0.6122 & 0.6375 & 0.6702 & 0.8214 & 0.5714 & 0.6250 & 0.4524 & 0.3700 & 0.6446 \\
\hline 0.7879 & 0.4900 & 0.4625 & 0.6702 & 1 & 0.5 & 0.5000 & 0.7810 & 0.2660 & 0.7109 \\
\hline 0.4848 & 0.6122 & 0.675 & 0.6808 & 0.7143 & 0.6286 & 0.7500 & 0.7143 & 0.3520 & 0.6817 \\
\hline 0.4545 & 0.7551 & 0.6000 & 0.6170 & 0.6071 & 0.5857 & 0.8125 & 0.6310 & 0.3520 & 0.7029 \\
\hline
\end{tabular}




\begin{tabular}{|l|l|l|l|l|l|l|l|l|l|}
\hline 0.4848 & 0.4900 & 0.6750 & 0.7021 & 0.9286 & 0.5714 & 0.7500 & 0.6858 & 1 & 0.7215 \\
\hline 0.5456 & 0.6327 & 0.6375 & 0.6808 & 0.7857 & 0.6000 & 0.6250 & 1 & 0.3900 & 0.9072 \\
\hline 0.5152 & 0.7551 & 0.575 & 0.5957 & 0.8214 & 0.4714 & 0.7500 & 0.7857 & 0.3530 & 0.8302 \\
\hline 0.3939 & 0.7347 & 0.6375 & 0.6383 & 0.8214 & 0.5286 & 0.8125 & 0.5643 & 0.2860 & 0.8700 \\
\hline
\end{tabular}

Table 6. Test File

\begin{tabular}{|c|c|c|c|c|c|c|c|c|}
\hline 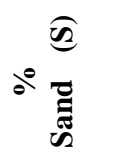 & $\therefore \begin{array}{l}\hat{E} \\
\bar{*}\end{array}$ & $\underset{0}{\vec{E}}$ & 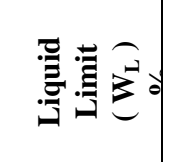 & 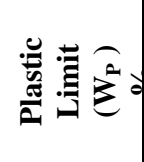 & 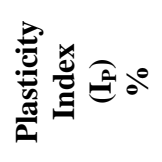 & 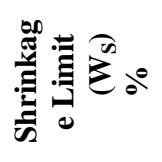 & 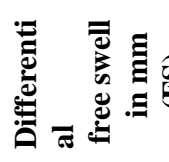 & 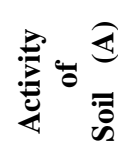 \\
\hline 0.364 & 0.582 & 0.756 & 0.708 & 0.848 & 0.571 & 0.506 & 0.326 & 0.286 \\
\hline 0.545 & 0.596 & 0.667 & 0.688 & 1.000 & 0.471 & 0.824 & 0.261 & 0.273 \\
\hline 0.576 & 0.694 & 0.602 & 1.000 & 0.909 & 0.557 & 0.588 & 0.283 & 0.356 \\
\hline 0.606 & 0.694 & 0.590 & 0.677 & 0.879 & 0.514 & 1.000 & 0.304 & 0.336 \\
\hline 0.515 & 0.796 & 0.864 & 0.698 & 0.909 & 0.524 & 0.647 & 0.326 & 0.361 \\
\hline
\end{tabular}

Note: Although five testing sets may seem few, they constitute $25 \%$ of the total date sets available for a present study.

Table 7. The various networks developed to model the expansive soils with MARE after 1000 iterations.

\begin{tabular}{|c|c|c|c|c|c|c|c|c|c|c|c|c|c|c|c|c|c|c|}
\hline in & 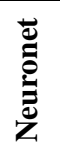 & $\begin{array}{l} \\
\dot{0} \\
\dot{8} \\
\dot{z}\end{array}$ & & & & & 颜递 & & & & & 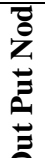 & $\begin{array}{l}\vec{\Xi} \\
\bar{\Xi} \\
\bar{E}\end{array}$ & 胥 & 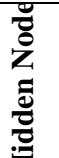 & $\sum_{\substack{x \\
\Sigma}}$ & $=$ & ชิ \\
\hline 1 & $\mathrm{~A} 1$ & 9 & $S$ & $\mathrm{M}$ & $\bar{C}$ & $\mathrm{~W}_{\mathrm{L}}$ & $\mathrm{W}_{\mathrm{P}}$ & $\mathrm{W}_{\mathrm{S}}$ & $\mathrm{I}_{\mathrm{P}}$ & A & FS & 1 & SP & 1 & 15 & 0.17 & 0.61 & 62.88 \\
\hline 2 & B1 & 9 & $\mathrm{~S}$ & $\mathrm{M}$ & C & $\mathrm{W}_{\mathrm{L}}$ & $\mathrm{W}_{\mathrm{P}}$ & $\mathrm{W}_{\mathrm{S}}$ & $\mathrm{I}_{\mathrm{P}}$ & A & FS & 1 & SP & 1 & 12 & 0.12 & -0.054 & 99.7 \\
\hline 3 & $\mathrm{C} 1$ & 9 & $S$ & $\mathrm{M}$ & $\mathrm{C}$ & $\mathrm{W}_{\mathrm{L}}$ & $\mathrm{W}_{\mathrm{P}}$ & $\mathrm{W}_{\mathrm{S}}$ & $I_{P}$ & A & FS & 1 & SP & 1 & 10 & 0.054 & 0.107 & 98.8 \\
\hline 4 & $\mathrm{C} 2$ & 9 & $\mathrm{~S}$ & $\mathrm{M}$ & C & $\mathrm{W}_{\mathrm{L}}$ & $\mathrm{W}_{\mathrm{P}}$ & $\mathrm{W}_{\mathrm{S}}$ & $\mathrm{I}_{\mathrm{P}}$ & $\mathrm{A}$ & FS & 1 & SP & \begin{tabular}{l|l|}
2 \\
\end{tabular} & 10 & 0.098 & 0.86 & 26.04 \\
\hline 5 & $\mathrm{C} 3$ & 9 & $\mathrm{~S}$ & $\mathrm{M}$ & $\mathrm{C}$ & $\mathrm{W}_{\mathrm{L}}$ & $\mathrm{W}_{\mathrm{P}}$ & $\mathrm{W}_{\mathrm{S}}$ & $\mathrm{I}_{\mathrm{P}}$ & A & FS & 1 & SP & 3 & 10 & 0.054 & 0.82 & 32.76 \\
\hline 6 & D1 & 8 & $\mathrm{~S}$ & $\mathrm{M}$ & $\mathrm{C}$ & $\mathrm{W}_{\mathrm{L}}$ & $\mathrm{W}_{\mathrm{P}}$ & $\mathrm{W}_{\mathrm{S}}$ & $\mathrm{I}_{\mathrm{P}}$ & & FS & 1 & SP & \begin{tabular}{l|l|} 
\\
\end{tabular} & 10 & 0.042 & -0.03 & 99.71 \\
\hline 7 & D2 & 8 & $\mathrm{~S}$ & $\mathrm{M}$ & $\mathrm{C}$ & $\mathrm{W}_{\mathrm{L}}$ & $\mathrm{W}_{\mathrm{P}}$ & $\mathrm{W}_{\mathrm{S}}$ & $\mathrm{I}_{\mathrm{P}}$ & & FS & 1 & SP & 2 & 10 & 0.044 & 0.104 & 98.90 \\
\hline 8 & D3 & 8 & $\mathrm{~S}$ & $\mathrm{M}$ & $\mathrm{C}$ & $\mathrm{W}_{\mathrm{L}}$ & $\mathrm{W}_{\mathrm{P}}$ & $\mathrm{W}_{\mathrm{S}}$ & $\mathrm{I}_{\mathrm{P}}$ & & FS & 1 & SP & 3 & 10 & 0.12 & -0.705 & 50.24 \\
\hline 9 & E1 & 7 & $\mathrm{~S}$ & $\mathrm{M}$ & $\mathrm{C}$ & $\mathrm{W}_{\mathrm{L}}$ & $\mathrm{W}_{\mathrm{P}}$ & $\mathrm{W}_{\mathrm{S}}$ & & & FS & 1 & SP & 1 & 10 & 0.118 & 0.138 & 98.10 \\
\hline $\begin{array}{l}1 \\
0 \\
\end{array}$ & E2 & 7 & $\mathrm{~S}$ & $\mathrm{M}$ & $\mathrm{C}$ & $\mathrm{W}_{\mathrm{L}}$ & $\mathrm{W}_{\mathrm{P}}$ & $\mathrm{W}_{\mathrm{S}}$ & & & FS & 1 & SP & 2 & 10 & 0.116 & -0.705 & 50.24 \\
\hline $\begin{array}{l}1 \\
1 \\
\end{array}$ & E3 & 7 & $\mathrm{~S}$ & $\mathrm{M}$ & $\mathrm{C}$ & $\mathrm{W}_{\mathrm{L}}$ & $\mathrm{W}_{\mathrm{P}}$ & $\mathrm{W}_{\mathrm{S}}$ & & & FS & 1 & SP & 3 & 10 & 0.07 & 0.138 & 98.1 \\
\hline 1 & $F$ & 9 & $\mathrm{~S}$ & $\mathrm{M}$ & C & $\mathrm{W}_{\mathrm{L}}$ & $\mathrm{W}_{\mathrm{P}}$ & $\mathrm{W}_{\mathrm{s}}$ & $\mathrm{I}_{\mathrm{P}}$ & A & FS & 1 & SP & 1 & 9 & 0.08 & - & - \\
\hline
\end{tabular}

Note: MARE : Means Average Relative Error, r: Root Mean Square Error, COD: Coefficient of Determination

\section{CONCLUSIONS}

In the present study, neuronets have been used to predict swelling pressure of both undisturbed as well as remolded soils from given geotechnical parameters such as grain-size distribution, consistency limits, specific gravity, deferential free swell etc. While the remolded soil neuronets developed in this study might be considered as specific, the undisturbed soil neuronets can be used to predict swelling characteristic for most soils of India. Similarly the combination of natural and remolded (i.e. data set used in training \& testing) may significantly assist earthwork engineers in designing \& constructing the sub-grade for roads, canals \& buildings etc. The swelling pressure of remolded clay was determined through "Constant Volume Method". However, the effect of the type of determination of swelling pressure and magnitude of swelling pressure is under investigation by the authors to cover wider range of applicability of swelling pressure neuronets to laboratory conditions irrespective of method of testing. Moreover, a neural network will be further used to prediction of expansion may assist the designers in selecting the appropriate water content to compact clays. Using a neural network concept, higher coefficients of determination were obtained despite the fact that in all cases the sets used in testing have never been used to train the networks. Another advantage of neuronets lies in the fact that such methods are early to develop and are able to investigate multi-related output phenomena. The ability of the neuronets to adopt the non linearity associated with the input parameters in relation to the output vector makes such neural networks powerful tools for modeling complex physical phenomena. Additionally whenever new soil data becomes available, they can be added to the database and a new braining phase can easily be carried out. This renders neural networks superior to regression models by avoiding the commonly used lengthy successive elimination procedures. Due to the observed good predictions of network to the 5 remolded soils collected from Ramtek, the original database containing 16 data sets can be expanded by adding these 5 data sets to it. Consequently, a new training for the database can be performed and a more general network can be obtained.

\section{ACKNOWLEDGEMENTS}

The Author wants to acknowledge the Hon. Management Pillai HOC College of Engineering and Technology for their wonderful encouragement and noteworthy to mention the best regards to our beloved HOD Civil Engineering for massive support while conducting experiments on soil samples.

During the preparation of the paper a word of advice was also 
received from Sarma, V.V.S., and Naresh Kumar Joshi, K.J., regarding usage of ANN to Engineering Applications and Rama Rao, R., Emeritus Professor. Department of Civil Engineering, A.U. College of Engineering, Andhra University, Visakhapatnam, A.P, India on laboratory testing of expansive soils.

\section{REFERENCES}

[1] Alpan, A. 1957 An apparatus for measuring the Swelling Pressure in Expansive Soil, Proceedings of the $4^{\text {th }}$ International Conference on Soil Mechanics \& Foundation Engineering, Hafia, Israil, Volume 1, 3-5.

[2] Dayakar, P. and Rongda, Z. 1999 Tri-axial compression behavior of sand \& gravel using artificial neural networks (ANN), Computers \& Geotechnics, 24: 228.

[3] Ghaboussi, J., Sidarta, D.E. and Lade, P.V. 1994 Neural network based modulating in geo-mechanics, Computer Methods \& Advances in Geo-mechanics, Sirivardhane \& Zaman (Ed), Balkema, Rotterdam, 163.

[4] Komornic, A. and David, D. 1969 Prediction of Swelling Pressure of Clays, Journal, Soil Mechanics and Foundation Division, American Society of Civil Engineers, Vol 95, SM1, 209 - 225.

[5] Livneh, M., Kassif, G., and Wiseman,G. 1969 The Use of Index Properties in the Design of Pavements on Expansive Clays, Proceedings, Second International Research and Engineering Conference on Expansive Clay Soils, Texas A\&M University, 218 - 234.
[6] Najjar, Y.M., Bashin, A.I, and Naoss, Wa.O. 1996 On Identification of Compaction Characteristics by Neuronets, Computers \& Geotechnics, 3: 173,177.

[7] Nayak, N.V. and Christensen, R.W. 1974 Swelling Characteristics of Compacted Expansive Soils, Clays and Clay Minerals, Vol 19, No. 4, 251-261.

[8] Seed, H. B., Woodward, R.J., Jr., and Lundgreen, R. 1962 Prediction of Swelling Potential for Compacted Clays, Journal, Soil Mechanics and Foundations Division, American Society of Civil Engineers, Vol 88, No.SM3, $53-87$.

[9] Shahim, M.A., Mair, H.R. and Jaksa, M.B. 2002 Predicting settlement of shallow foundation using neural network, Journal of Geotechnical \& Geo-Environmental Engineering, 790- 791.

[10] Sullivan, R. A. and Mc Clelelland, B. 1969 Predicting heave of Buildings on Unsaturated Clay, Proceedings, Second International Research and Engineering Conference on Expansive Clay Soils, Texas A\&M University, College Station, Texas, $404-420$.

[11] Vijayvergiya, V. N. and Sullivan, R. A. 1973 Simple Technique for Identifying Heave Potential, Proceedings, Workshop on Expansive Clays And Shales in Highway Design And Construction, D.R.Lamb and S.J.Hanna, ed., Prepared for Federal Highway Administration, Washington,D.C., Vol 1, 275-294. 